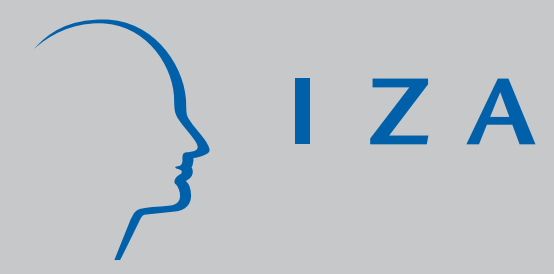

IZA DP No. 1693

Can Democracy Educate a Society?

Hans Gersbach

Lars Siemers

July 2005 


\title{
Can Democracy Educate a Society?
}

\author{
Hans Gersbach \\ CER-ETH Zurich, \\ CEPR and IZA \\ Lars Siemers \\ RWI Essen
}
Discussion Paper No. 1693
July 2005
(updated: July 2010)

\author{
IZA \\ P.O. Box 7240 \\ 53072 Bonn \\ Germany \\ Phone: +49-228-3894-0 \\ Fax: +49-228-3894-180 \\ Email: iza@iza.org
}

\begin{abstract}
Any opinions expressed here are those of the author(s) and not those of the institute. Research disseminated by IZA may include views on policy, but the institute itself takes no institutional policy positions.
\end{abstract}

The Institute for the Study of Labor (IZA) in Bonn is a local and virtual international research center and a place of communication between science, politics and business. IZA is an independent nonprofit company supported by Deutsche Post World Net. The center is associated with the University of Bonn and offers a stimulating research environment through its research networks, research support, and visitors and doctoral programs. IZA engages in (i) original and internationally competitive research in all fields of labor economics, (ii) development of policy concepts, and (iii) dissemination of research results and concepts to the interested public.

IZA Discussion Papers often represent preliminary work and are circulated to encourage discussion. Citation of such a paper should account for its provisional character. A revised version may be available directly from the author. 
IZA Discussion Paper No. 1693

July 2005 (updated: July 2010)

\section{ABSTRACT}

\section{Can Democracy Educate a Society?*}

We examine the constitutional design required for democratic societies to overcome poverty traps. Restricting agenda-setting only by ensuring subsistence levels of consumption and applying simple majority voting as decision rule fails to enable a society to overcome poverty because it does not induce capital-enhancing redistribution. We show that a combination of suitable constitutional rules can, however, overcome poverty and induce economic wellbeing. Besides majority voting, these rules include rotating agenda-setting, agenda repetition and tax protection rules. We highlight the crucial role of democratic institutions for economic development and discuss why the evidence for democracy fostering growth is mixed.

JEL Classification: D72, E62, H23, H53, O11

Keywords: constitutional design, institutions, redistribution, poverty traps, tax allowances, voting rules

Corresponding author:

Hans Gersbach

CER-ETH - Center of Economic Research

at ETH Zürich

Zürichbergstrasse 18

8092 Zürich

Switzerland

E-mail: hgersbach@ethz.ch

\footnotetext{
* This is a substantial revision of the version originally posted in July 2005. We would like to thank Clive Bell, Ivo Bischoff, Jürgen Eichberger, Felix Mühe, and participants of a seminar in Heidelberg and of the 1st World Meeting of the Public Choice Societies in Amsterdam in 2007 for helpful comments.
} 


\section{Introduction}

There is an ongoing debate about whether democratization is a precondition for economic well-being. Theoretical and empirical investigations have produced contradictory conclusions on the question of whether democracy fosters growth. The empirical results on the issue whether economic development causes democratization (Grand Transition view or Lipset's Law) or whether economic development is a consequence of democratization (Primacy of Institutions view or Reverse Lipset Law) are mixed and do not produce a robust assessment (Barro, 1996; Perotti, 1996; Durham, 1999; Tavares and Wacziarg, 2001; Paldam, 2007; Paldam and Gundlach, 2008). Theoretical models that would help us understand how democracy impacts on economic development, and vice versa, are rare. In this paper we develop a model that highlights why democracy may fail to foster development and how democracies must be designed to avoid this failure.

We analyze an endogenous growth model in which capital accumulation is the source of growth. As poor households cannot afford to invest, they are caught in a poverty trap. Bell and Gersbach (2009) show how such a vicious circle can be overcome by a dynamic scheme of taxes and subsidies. The crucial question is whether there exists a policy scheme that can be implemented successfully in democracy. Does democracy allow for policies that overcome poverty traps? What premises have to be fulfilled in order to guarantee success? Is a certain degree of dictatorship necessary to alleviate poverty and to start economic development? In this paper we address these political-economy questions. In particular, we ask whether there are constitutional agenda and decision rules that induce a transition from poverty to basic economic wealth.

Our main findings are as follows: (i) a democracy with a simple majority rule and only weakly restricted agenda rights will not achieve growth-promoting redistribution and will remain in the poverty trap indefinitely; (ii) a democracy with a simple majority rule and a given benevolent agenda setter can overcome poverty (benchmark); (iii) without a benevolent agenda-setter, escape from poverty is also possible once the combination of flexible majority rules, a rotating agenda-setting rule, and an agenda-repetition rule is introduced. An alternative solution is a combination of a simple majority rule with rotating agenda-setting, agenda repetition, and an augmented tax allowance. 
The overall conclusion from our analysis is that there are democratic institutions that can engineer a transition from a state of backwardness to welfare and continuous growth. Deviations from these constitutional designs, however, lead to an absence of economic development. The constitutional rules thus represent necessary preconditions if democracy is to bring about economic development.

The paper is organized as follows: Section 2 surveys the related literature, and Section 3 describes the model. Section 4 explains the tax-and-subsidy scheme for overcoming the poverty trap, and Section 5 develops the political framework. Section 6 shows as a benchmark case that a democracy with benevolent, but dictatorial agenda-setting can escape poverty. Section 7 demonstrates that a democracy consisting of self-interested individuals is unable to escape poverty traps unless particular constitutional constraints on the agenda-setter are established. Finally, Section 8 discusses potential political failures, which rules could cure these, and which rules in the constitutions of the U.S. and Germany are related. Section 9 concludes.

\section{Relation to the Literature}

Our constructive constitutional-economics approach goes back to Buchanan and Tullock (1962). A survey on "fiscal constitutionalism" is given, for instance, by Brennan and Eusepi (2005). In particular, we draw on the work pertaining to optimal majority rules in the context of reforms and public goods provision (Aghion and Bolton, 2003; Aghion et al., 2004; Gersbach, 2005). Building on these insights, we develop a flexible majority rule in which the required majority depends on the proposal itself and induces growth-enhancing redistribution.

Our paper is also related to the political-economy literature focusing on inter-generational redistribution policies. In Gradstein and Justman (1997), agents can choose between subsidies for privately purchased education and free uniform public provision, both financed by a proportional income tax. Saint-Paul and Verdier (1993), in their turn, apply the median-voter approach to tax-financed public education. We focus on the special environment of developing economies and analyze the dynamic political economy of intragenerational redistribution escaping poverty traps by accumulating capital. 
Grossman and Helpman (1998) emphasize that if an agenda-setter suspects that transfers to the young will be reversed by future politicians, he will be tempted to cater to the old instead. This can lead to policies that are detrimental both to the young and to growth. Grossman and Helpman stress that though a polity might try to introduce constitutional constraints on the extent of such politically-motivated redistribution, it may be difficult to write a constitution that would distinguish "strategic" from well-intentioned redistribution. We examine whether democratic constitutions can induce a society to set up dynamic redistribution schemes in such a way that all individuals are provided with at least a basic degree of capital. We highlight the fact that appropriate constitutional rules can lead to welfare-enhancing redistribution from the parent generation to the children, and hence to long-term welfare. But even small deviations from such rules can make democracy fail to engineer growth.

A related study is that of Rangel (2005). He finds that introducing a constitutional amendment stipulating that debt and intergenerational public goods must be financed with land taxes would make intergenerational expropriation impossible and can induce optimal investments. In our analysis, constitutional rules have to prevent intra-generational expropriation.

Persson and Tabellini (2006) state that, in principle, democracy promotes economic development, but the effect depends on the details of democratic reforms (e.g. the sequence of democratization and economic liberalization) as well as on the form of government and the electoral system. Keefer and Vlaicu (2007) also emphasize the problem of credibility in new democracies. In this paper, we identify specific constitutional rules that help democracy to promote economic development.

Our paper is also related to the substantial body of literature on the political economy of growth and (intra-generational) redistribution. This literature has explored whether more unequal societies tend to favor more redistribution and whether more redistribution is harmful to growth. In Alesina and Rodrik (1994) or Persson and Tabellini (1994), inequality is harmful to growth, as it causes inefficient redistribution via the political process. Saint-Paul and Verdier $(1993,1996)$ have shown that more redistribution toward public education is positively correlated with growth. Perotti $(1992,1993,1996)$ demonstrates that the question whether redistribution is harmful to growth may depend on the 
level of development and the resulting political equilibrium. In our model, redistribution may be either positive or negative, depending on the type of redistribution and the set of constitutional rules. We propose constitutional rules ensuring that only growth-promoting redistribution occurs.

\section{The Model}

We use a non-overlapping generations model (cf. Saint-Paul and Verdier, 1993). There is an infinity of generations. Each generation consists of a continuum of households represented by interval $[0,1]$. Each individual of a household $i \in[0,1]$ within a generation $t$ lives for one period and has one offspring in generation $t+1$. Individuals supply labor inelastically and earn a fixed income $w$ by pure labor. Moreover, there is a second factor $x$ that can be used in production to increase income. This factor could be interpreted as some broadly defined capital good, but in our approach this factor represents human capital. The level of human capital in $t+1$, denoted by $x_{i, t+1}$, comes in part from the parent's level of human capital, denoted by $x_{i t}$, due to positive spill-over effects and in part from investments $e_{i t}$ in the offspring's education undertaken by the parent (Bell and Gersbach, 2009). ${ }^{1}$ Thus we assume

$$
x_{i, t+1}=g\left(x_{i t}, e_{i t}\right) \geq 0,
$$

where $g(\cdot)$ is a twice differentiable and continuous function with $\frac{\partial g(\cdot)}{\partial x_{i t}}>0, \frac{\partial g(\cdot)}{\partial e_{i t}}>0$, $0 \leq g\left(x_{i t}, 0\right)<x_{i t}$ as long as $x_{i t}>0$, and $g(0,0)=0$. Human capital $x_{i t}$ generates income $f\left(x_{i t}\right)$, where $f(0)=0$ and $f(\cdot)$ is a continuously increasing and differentiable function. Capital markets are imperfect, as poor individuals cannot borrow against future income. This has been widely discussed and justified in the literature (cf., e.g., Baland and Robinson, 2000, p. 670). Accordingly, the individual budget constraint is given by

$$
c_{i t}+e_{i t} \leq w+f\left(x_{i t}\right)
$$

where $c_{i t}$ is the consumption of individual $i$ in period $t$. While it is possible to incorporate $w$ in $f(\cdot)$, it will be more transparent to separate income related to individual investments

\footnotetext{
${ }^{1}$ Parents invest in the education of their children by sending the children to school and teaching them how to maintain capital and to produce. In doing so, the formation of human capital is positively correlated with the parents' level of human capital via child rearing and other forms of parental care (Bell and Gersbach, 2009).
} 
from the fixed income generated by pure labor.

\subsection{Behavior of Individuals}

Alongside consumption, individuals also care about the level of capital $x_{i, t+1}$ of their offspring (cf. Banerjee and Newman, 1993; Galor and Zeira, 1993; Saint-Paul and Verdier, 1993). This particular type of altruism comes from the "joy of giving" motive behind bequests, where parents care about particular aspects that they deem to be important for their children without knowing a priori how their offspring value these aspects (SaintPaul and Verdier, 1993, p. 401). Thus, individuals are assumed to maximize a utility function $U\left(c_{i t}, x_{i, t+1}\right)$, which is assumed to be strictly quasi-concave with positive and decreasing marginal utilities in $c_{i t}$ and $x_{i, t+1}$. This implies that the budget constraint will be exhausted and (2) will hold as an equality. Since $x_{i, t+1}=x_{i, t+1}\left(e_{i t}\right)$ individuals have only one independent choice variable, $e_{i t}{ }^{2}$ The optimal choice is denoted by $e_{i t}^{*}$ and the resulting optimal consumption by $c_{i t}^{*}$. Using (1) and (2) they are given as

$$
\begin{aligned}
e^{*}\left(x_{i t}\right) & =\underset{\left\{e_{i t}\right\}}{\operatorname{argmax}} U\left[w+f\left(x_{i t}\right)-e_{i t}, g\left(x_{i t}, e_{i t}\right)\right] \\
c^{*}\left(x_{i t}\right) & =w+f\left(x_{i t}\right)-e^{*}\left(x_{i t}\right) .
\end{aligned}
$$

The Kuhn-Tucker maximum condition is given by

$$
\frac{\mathrm{d} U}{\mathrm{~d} e_{i t}}=\frac{\partial U(\cdot)}{\partial c_{i t}}+\frac{\partial U(\cdot)}{\partial x_{i, t+1}} \cdot \frac{\partial g(\cdot)}{\partial e_{i t}} \leq 0 \quad \text { and } \quad \frac{\mathrm{d} U}{\mathrm{~d} e_{i t}} \cdot e_{i t}=0
$$

We follow the standard assumption that altruism is not operative if households are very poor (cf. Basu, 1999; Bell and Gersbach, 2009; Gersbach and Siemers, 2009). That is, individuals demand a minimum level of consumption, labeled $\bar{c}$, before they are willing to invest in their children. Consequently, $\bar{c}$ determines a threshold level of income that has to be exceeded before any investment $e_{i t}>0$ is undertaken. This, in turn, determines a threshold level of human capital, $\bar{x}$, that is defined implicitly by $\bar{c}=w+f(\bar{x})$. In term of the utility function we assume that

$$
\frac{\partial U\left(c_{i t}, x_{i, t+1}\right)}{\partial x_{i, t+1}}\left\{\begin{array}{lll}
=0 & \text { if } & c_{i t} \leq \bar{c} \\
>0 & \text { if } & c_{i t}>\bar{c}
\end{array}\right.
$$

\footnotetext{
${ }^{2}$ In order to ensure the second-order condition for a maximum to hold, we assume the Hessian of $U\left(c_{i t}, x_{i, t+1}\left(e_{i t}\right)\right)$ to be negatively semi-definite. For a discussion of the issue see Siemers (2005, pp. 139-141).
} 
We finally assume that both goods are normal, i.e. $\frac{\partial c^{*}\left(x_{i t}\right)}{\partial x_{i t}}>0$ and $\frac{\partial e^{*}\left(x_{i t}\right)}{\partial x_{i t}}>0$ for $x_{i t}>\bar{x}$, which implies, ceteris paribus,

$$
e^{*}\left(x_{i t}\right) \begin{cases}=0 & \text { for all } x_{i t} \leq \bar{x} \\ >0 & \text { otherwise. }\end{cases}
$$

It follows from (2) that $c^{*}\left(x_{i t}\right)=w+f\left(x_{i t}\right) \leq \bar{c}$ as long as $x_{i t} \leq \bar{x}$, otherwise $w+f\left(x_{i t}\right)>$ $c^{*}\left(x_{i t}\right)>\bar{c}$.

\subsection{Dynamics}

The engine of growth in our model is described by the law of motion given in (1). Incorporating the individual's optimal behavior, we obtain

$$
x_{i, t+1}= \begin{cases}g\left(x_{i t}, 0\right) \in[0, \bar{x}) & \text { for all } x_{i t} \leq \bar{x} \\ g\left(x_{i t}, e_{i t}^{*}\left(x_{i t}\right)\right) & \text { for all } x_{i t}>\bar{x}\end{cases}
$$

The model has the following locally stable poverty trap: if $x_{i t}=0$, an individual will not invest, i.e. $e^{*}\left(x_{i t}\right)=0$, so that $x_{i, t+1}=g(0,0)=0$. Thus, $\left(x_{i, t+1}, x_{i t}\right)=(0,0)$ for all $t$ is a steady state. Due to $g\left(x_{i t}, 0\right)<x_{i t}$ for $x_{i t} \in(0, \bar{x})$, this steady state is locally stable and represents a poverty trap. We next consider the trajectory in the $\left(x_{i, t+1}, x_{i t}\right)$ space and differentiate $x_{i, t+1}=g\left(x_{i t}, e^{*}\left(x_{i t}\right)\right)$ with respect to $x_{i t}$ :

$$
\frac{\mathrm{d} x_{i, t+1}}{\mathrm{~d} x_{i t}}=\frac{\partial g(\cdot)}{\partial x_{i t}}+\frac{\partial g(\cdot)}{\partial e_{i t}} \cdot \frac{\partial e^{*}(\cdot)}{\partial x_{i t}}
$$

We have assumed $\frac{\partial g(\cdot)}{\partial x_{i t}}>0, \frac{\partial g(\cdot)}{\partial e_{i t}}>0$, and $\frac{\partial e^{*}\left(x_{i t}\right)}{\partial x_{i t}}>0$. It follows that the trajectory has a positive slope. Because of $\frac{\partial e^{*}\left(x_{i t}\right)}{\partial x_{i t}}=0$ for $x_{i t}<\bar{x}$, our assumption $x_{i, t+1}<x_{i t}$ for $x_{i t} \in(0, \bar{x}]$ requires that $\frac{\partial g(\cdot)}{\partial x_{i t}}<1$. We assume that $\frac{\partial g\left(x_{i t}\right)}{\partial e_{i t}} \cdot \frac{\partial e^{*}\left(x_{i t}\right)}{\partial x_{i t}}+\frac{\partial g\left(x_{i t}\right)}{\partial x_{i t}}>1$ if $x_{i t}>\bar{x}$. The phase diagram is given in Figure 1. At $\tilde{x}$ the trajectory intersects the $45^{\circ}$ line a second time, so that there is a second steady state at $(\tilde{x}, \tilde{x})$. If $x_{i t}<\tilde{x}$, the capital stock $x$ decreases and runs into the poverty trap, whereas it increases if $x_{i t}>\tilde{x}$. If we denote the growth rate of factor $x_{i t}$ by $\gamma_{x_{i t}}\left(\gamma_{x_{i t}}=\frac{x_{i t}-x_{i t-1}}{x_{i t-1}}\right)$, the growth pattern can be summarized as follows:

$$
\gamma_{x_{i t+1}} \begin{cases}>0 & \text { if } \quad x_{i t}>\tilde{x} \\ <0 & \text { if } \quad 0<x_{i t}<\tilde{x} \\ =0 & \text { if } \quad x_{i t}=0 \quad \text { or } \quad x_{i t}=\tilde{x} .\end{cases}
$$

Thus, the poverty trap at $x_{i t}=0$ is locally stable in the area $x_{i t} \in[0, \tilde{x})$, while the second steady state at $\tilde{x}$ is unstable. In the appendix we provide a specific example. 


\section{Redistribution via Tax/Subsidy Schemes}

To analyze whether democratic countries can overcome poverty, we consider redistribution via subsidies and taxation. The basic idea is as follows: If individuals are too poor to invest, their wealth levels must be increased in order to foster private wealth accumulation. In our setting, an individual requires a stock of (human) capital higher than $\tilde{x}$ to attain the sphere of sustainable economic growth. We use $s_{i t}>0$ to denote the subsidy a household $i$ receives in period $t$. As a worst-case scenario, we assume that policy-makers do not have access to international capital markets. That is, subsidies have to be financed completely by taxes; the tax a household $i$ has to pay in period $t$ we denote by $\tau_{i t} \geq 0$.

The question is whether there exists a redistribution scheme that allows the society to escape poverty under democratic rules. We assume that a household is either subsidized or taxed. We keep both types of households (taxed and subsidized) separately in order to increase the transparency of the analysis. For subsidized households, $e^{*}(\cdot)$ is determined by income $w+f\left(x_{i t}\right)+s_{i t}$ and therefore can be written as $e^{*}\left(x_{i t}, s_{i t}\right)$ with $\frac{\partial e^{*}(\cdot)}{\partial s_{i t}}>0$ if the interior solution holds. We fix some arbitrarily small $\epsilon>0$. Then, we define $\tilde{s}\left(x_{i t}\right)$ by $g\left(x_{i t}, e^{*}\left(x_{i t}, \tilde{s}\left(x_{i t}\right)\right)\right)=\tilde{x}+\epsilon$. Thus, $\tilde{s}\left(x_{i t}\right)$ is a subsidy that induces escape from poverty permanently, ${ }^{3}$ because $g\left(x_{i t}, e^{*}\left(x_{i t}, \tilde{s}\left(x_{i t}\right)\right)\right)>\tilde{x}$ and capital accumulation begins.

For taxed households, income is $w+f\left(x_{i t}\right)-\tau_{i t}$, and optimal investment can be written as $e^{*}\left(x_{i t}, \tau_{i t}\right)$ with $\frac{\partial e^{*}(\cdot)}{\partial \tau_{i t}}<0$. Similarly to $\tilde{s}\left(x_{i t}\right)$ we define $\tilde{\tau}\left(x_{i t}\right)$ by $g\left(x_{i t}, e^{*}\left(x_{i t}, \tilde{\tau}\left(x_{i t}\right)\right)\right)=$ $\tilde{x}+\epsilon$. Hence, a household taxed by $\tilde{\tau}\left(x_{i t}\right)$ has a capital stock that remains above $\tilde{x}$ in the next period.

To formulate the government's budget constraint, we reinterpret the indexation of households as a real valued function on $[0,1]$. Total revenue in period $t$ is denoted by $R_{t}$ and amounts to $\int_{0}^{1} \tau_{t}(i) \mathrm{d} i$. Similarly, subsidy expenditures amount to $\int_{0}^{1} s_{t}(i) \mathrm{d} i$. Thus, the budget constraint in period $t$ is given by

$$
\int_{0}^{1} \tau_{t}(i) \mathrm{d} i \geq \int_{0}^{1} s_{t}(i) \mathrm{d} i .
$$

\footnotetext{
${ }^{3}$ There does not exist a minimal subsidy with this property, but any other subsidy level that does the trick and is below $\tilde{s}\left(x_{i t}\right)$ is arbitrarily close to $\tilde{s}\left(x_{i t}\right)$.
} 


\section{Initial Conditions}

We assume that a rich elite owns all human capital in $t=0$. This elite constitutes a fraction $\psi$ of the society, with $0<\psi<1 / 2$. Those individuals are indexed by $i \in[0, \psi]$. Each member of this elite is assumed to have a human capital level of $x_{i 0}>\tilde{x}$. The other fraction of the society, $1-\psi$, is poor, has no human capital, and can only afford the subsistence level of consumption $c^{s u b}=w<\bar{c}$. These households are in the poverty trap.

\section{The Political Economy Framework}

We adopt the standard constitutional approach to political decision-making (Buchanan and Tullock, 1962). In the first, constitutional stage, societies decide under a veil-ofignorance about the rules that govern legislative processes. In the second, legislative stage, the individuals decide on actual policies, given the rules stated in the constitution.

Our primary interest is whether there exist democratic constitutions that induce literacy and growth. ${ }^{4}$ At the legislative stage, we consider the case of a direct democracy with citizens $i \in[0,1]$. This is equivalent to a parliamentary democracy that represents unbiased citizens of the state (cf. also Helpman, 1997). We assume that all voters have the same voting and agenda rights. To build a constitution consisting of several rules we introduce first some basic rules which will be used throughout the paper. For that purpose, we denote by $P_{t}=\left\{\left(\tau_{i t}, s_{i t}\right)\right\}_{i=0}^{1}$ a tax/subsidy proposal. Rules for proposal-making will be introduced later. We define:

- Majority voting (MV): If a proposal receives a majority of $m=\frac{1}{2}$ of the votes, it passes legislation. ${ }^{5}$ Otherwise the status quo prevails.

We restrict the set of proposals allowed to one that satisfies the governmental budget constraint with the agenda rule $B C$.

- Budget constraint (BC): A constitutional proposal has to satisfy the budget constraint stated in equation (9).

\footnotetext{
${ }^{4}$ Such constitutions would be chosen under a veil-of-ignorance. In section 8 we discuss, however, the circumstances why societies do not choose such constitutions in practise.

${ }^{5}$ In fact, the majority rule usually states that a proposal will be adopted if more than half of the citizens support it. As a tie-breaking rule we assume the adoption of a proposal if $m=\frac{1}{2}$. Otherwise, we would need to work with $m=\frac{1}{2}+\epsilon, \epsilon$ sufficiently small. Qualitatively, the results would be the same.
} 
We additionally assume that the constitution guarantees a subsistence level of consumption to all members of the society. Referring to tax law this requires:

- Subsistence level rule (SLR): Households are guaranteed a personal tax exemption amounting to $c^{s u b}$.

For the analysis later on we note that citizens will vote sincerely as they only vote once and there will be a yes/no voting decision. Hence, voter $i$ will support proposal $P_{t}$ if $s_{i t}>0$ and reject it if $\tau_{i t}>0$. To break tie we assume that voter $i$ will support a proposal $P_{t}$ if $s_{i t}=\tau_{i t}=0$. Given the tie-breaking rule, a proposal is accepted if, and only if, the share of individuals not being taxed is at least $\frac{1}{2}$.

We use $T$ to denote the number of periods the society needs to escape poverty. In the following two sections we specify two different ways how proposals are made.

\section{Democracy with a Benevolent Agenda-Setter}

We first investigate as a benchmark case whether the three basic rules $\{M V, B C, S L R\}$ enable a society to escape from poverty if the proposal is made by a benevolent agenda setter. Such an agenda setter has the sole objective to overcome poverty in all households $i \in[0,1]$. Policy proposals from this agenda setter, however, need the required majority stated in the constitution to pass legislation. Such a democracy is called a democracy with a benevolent agenda setter.

The non-capital-owning individuals of fraction $1-\psi$ are caught in the poverty trap at $x_{i t}=0$. If the benevolent agenda-setter wants to overcome poverty in $T$ periods, then, over $T$ periods the fraction $1-\psi$ has to be subsidized. For a proposal to be accepted in period $t$, the maximum fraction of the society to be taxed is $\frac{1}{2}$, because otherwise a majority would vote against the tax/subsidy proposal. Additionally, because of SLR and $c_{i 0}=c^{s u b}$ for all $i \in(\psi, 1]$, only members of the elite can be taxed in period $t=0$. We obtain

\section{Proposition 1}

A democracy with a benevolent agenda-setter, $\psi>0$ and a constitution $C\{B C, S L R$, $M V\}$ can overcome poverty in finite time. 
Proof : We define the tax rate $\hat{\tau}$ implicitly by:

$$
x_{i 0}=g\left(x_{i 0}, e^{*}\left(x_{i 0}, \hat{\tau}\right)\right)
$$

Hence, $\hat{\tau}$ is the tax that allows the elite to stay at the human capital level $x_{i 0}$. As $x_{i 0}>\tilde{x}$ and $g\left(x_{i 0}, e^{*}\left(x_{i 0}, 0\right)\right)>x_{i 0}$ we obtain that $\hat{\tau}>0$ as $e^{*}(\cdot, \cdot)$ and $g(\cdot, \cdot)$ are continuous functions. Let $\delta_{t}$ denote the fraction of subsidized households in period $t$. Choosing $\delta_{0}=\frac{\psi \hat{\tau}}{\tilde{s}(0)}$ maximizes $\delta_{0}$ while complying with the $\mathrm{BC}$ rule. Then, consider the following proposal in $t=0$ :

$$
P_{0}= \begin{cases}\hat{\tau} & \forall i \in[0, \psi] ; \\ s_{i 0}=\tau_{i 0}=0 & \forall i \in\left(\psi, 1-\delta_{0}\right] ; \\ s_{i 0}=\tilde{s}(0) & \forall i \in\left(1-\delta_{0}, 1\right] .\end{cases}
$$

This proposal will be supported by more than $50 \%$ of voters $(\psi<1 / 2)$ and thus will be adopted. The benevolent agenda setter can repeat the same proposal in each period by shifting subsidization sequentially from $\left(1-\delta_{0}, 1\right]$ to $\left(1-2 \delta_{0}, 1-\delta_{0}\right],\left(1-3 \delta_{0}, 1-2 \delta_{0}\right]$ etc. Hence, after $T:=\left[\frac{1-\psi}{\delta_{0}}\right]$ the entire society has human capital strictly above $\tilde{x}$ and thus poverty is eliminated. ${ }^{6}$

It is important to stress that the procedure used in the proof of Proposition 1 may not be the one that minimizes the time span needed to educate the society. For instance, subsidized households can also be taxed over time and it may be useful to provide larger subsidies to a smaller target group in order to increase the taxable capacity of the economy. It may also be useful to vary the tax rates of the elite over time to further increase the taxable capacity. ${ }^{7}$ The essential point of Proposition 1 is, however, that a benevolent agenda-setter can shift taxation and subsidization over time so that poor households will invest sufficiently in factor $x_{t+1}$ and, once they have been lifted out of the poverty trap, households are protected from excessive taxation so that they do not fall back into poverty.

\section{When Multiple Subsidization Is Required}

If we interpret $e_{i t}$ as the fraction of the offspring's time used for schooling (Bell and Gersbach, 2009), such investments have an upper bound: $0 \leq e_{i t} \leq 1$. Hence, the maximum

\footnotetext{
$6\left[\frac{1-\psi}{\delta_{0}}\right]$ denotes the smallest integer greater or equal to $\frac{1-\psi}{\delta_{0}}$.

${ }^{7}$ We restricted taxation in the proof to at most reducing income growth to zero: $x_{i, t+1}=x_{i t}$. This restriction could also be lowered to $x_{i, t+1}>\tilde{x}$, which would increase the tax potential in the first period. Given that $\frac{\partial \gamma_{x_{t}}}{\partial x_{t}}>0$ (as in our example in section A, eq. (14)), the effect on the tax potential in succeeding periods is, however, negative.
} 
level of human capital attainable in the period following (first) subsidization, denoted by $x_{i, t+1}^{\max }$, is given by $g(0,1)$. If this maximum level is below $\tilde{x}$, one-time subsidization will not suffice to escape poverty because $\gamma_{x_{i t}}<0$ : the household will again become fully impoverished over time and a one-time subsidy produces only temporary success. Multiple subsidizing of a single household, however, augments the household's human capital $x_{i}$ to a level higher than $\tilde{x}$ in, say, $l$ periods. After $l$ periods, a single household exceeds the threshold value $\tilde{x}$, and we can apply the same construction as in Proposition 1 to multiple subsidization. A targeted group is subsidized $l$ times and then, the agenda setter switches to the next target group. We thus obtain:

\section{Corollary 1}

A democracy with a benevolent agenda-setter, $\psi>0$ and a constitution $C\{B C, S L R$, $M V\}$ can overcome poverty in finite time even if $x_{i, t+1}^{\max }<\tilde{x}$.

Overall, a benevolent democratic agenda-setter can introduce a successful redistribution policy for overcoming poverty over time.

\section{Democratic Agenda-Setting}

In the Public Choice tradition of the agency problem between government and citizens we now consider democratic agenda-setting with self-interested rational individuals proposing agendas (e.g. Frey, 1983; Shughart and Tollison, 2005; Mueller, 2006; Brennan, 2008; Grant, 2008). We use a standard democratic rule to determine the proposal-maker:

- Random agenda setting (RAS): The agenda-setter of a period $t$ is randomly selected from the members of the population.

Random selection is a method for choosing a proposal-maker fulfilling the democratic requirement that each person should have the same chance to make a proposal (anonymity principle). It is widely used in the literature on political science and political economy (Mueller et al., 1972; Baron and Ferejohn, 1989; Frey and Stutzer, 2006) and actually used in India, for instance (Duflo, 2005, p. 669). 


\subsection{The Impossibility Result}

We now ask whether Proposition 1 also holds in this more realistic extended setting.

\section{Proposition 2}

A democracy with $\psi>0$ and $C\{B C, S L R, R A S, M V\}$ can not overcome poverty in finite time.

Proof : Suppose that an individual $i$ is recognized randomly as agenda-setter in a particular period $t$. In order to obtain the maximal amount of subsidies, this individual $i$ will maximize the tax revenue. ${ }^{8}$ Hence, since there are no restrictions other than retaining a consumption level $c^{s u b}$, half of the population will be taxed according to $\tau_{t}\left(x_{i t}\right)=$ $w+f\left(x_{i t}\right)-c^{s u b}$. Consequently, in each single period $t$, for all time, half of the society will not invest at all. Thus, in each period, at least half of the society remain in a state of backwardness.

Proposition 2 is a dynamic variant of the general characteristic of majority voting rules that majorities can expropriate minorities ("tyranny of the majority"), as has been shown in Riker (1962), Mueller (1979, pp. 116-117) or Bernholz and Breyer (1994, Sect. 11.3). In our context, this generates a high degree of inefficiency since in the future every household able to escape poverty will belong to a minority. ${ }^{9}$

\subsection{Poverty-Overcoming Constitutions}

We have seen that the democratic rules used in the last subsection were not sufficient to induce literacy and growth. However, we now demonstrate that there exist suitable constitutional rules that enable democracies to overcome poverty.

\footnotetext{
${ }^{8}$ As we have a continuum of voters, strictly speaking the subsidy for the agenda setter becomes infinite. If we consider a group of agents with positive measure having the right to determine the agenda, then subsidies of agenda setters remain finite.

${ }^{9}$ When migration is possible, an agenda setter may even choose extreme policies in order to encourage citizens, that may vote in the future in favor of agendas that are harmful for him and his constituents, to emigrate (Glaeser and Shleifer, 2005; Brueckner and Glazer, 2007). This way of shaping the future electorate represents a particular subtle form of majorities expropriating minorities.
} 
We introduce a tax protection rule. Actual protection rules will be discussed extensively in section 8. In the model, such protection requires that we extend our personal tax allowance of size $c^{\text {sub }}$ (SLR) with the following rule:

- Claim on investment allowance (CIA[a]): Every household has a claim on a fixed tax allowance amounting to $a>0$ to maintain the level of capital sufficient to save itself from lapsing into poverty.

Overall, the objective of the CIA rule is to guarantee all citizens a level of tax-free income required to invest in the maintenance of the minimum stock of capital required to avoid impoverishment. The CIA rule can be understood as property rights on (human) capital which have been found to have significant effects on investment and growth (Knack and Keefer, 1995).

An alternative instrument for guaranteeing the protection required is flexible majority rules, introduced by Gersbach $(2004,2005)$. Under flexible majority rules, the required majority depends on the proposal itself. We denote net income $w+f\left(x_{i t}\right)-\tau_{i t}$ by $v_{i t}$ and introduce the following voting rule:

- Threshold flexible majority rule $(\mathrm{TFM}[\bar{v}])$ : The required majority $m_{t}$ jumps from $\frac{1}{2}$ to 1 if the net income $v_{i t}$ of any household $i \in[0,1]$ is lowered by taxation below the constitutional income threshold $\bar{v}$ :

$$
m_{t}=\left\{\begin{array}{llll}
\frac{1}{2} & \text { if } & v_{i t} \geq \bar{v} & \text { for all } i \in[0,1] \\
1 & \text { if } & v_{i t}<\bar{v} & \text { for any } i \in[0,1]
\end{array}\right.
$$

Note that - in contrast to the CIA rule - the TFM rule allows any kind of agenda. However, if an agenda involves taxation that reduces net income of any household below a particular limit $\bar{v}$ stated in the constitution, the agenda will only pass legislation if all citizens agree. Hence, each citizen has a veto right against excessive taxation, where the constitution determines via $\bar{v}$ what is "excessive".

We next introduce a new rule for agenda setting. For that purpose we denote by $h$ a coalition (or interest group) of citizens that represent a fraction of the society with measure $\Delta(0<\Delta<1)$. We assume for ease of presentation that $\frac{1}{\Delta}$ is a natural number $N$. Hence, we have $N$ coalitions labeled by $h$, where $h \in\{1, \ldots, N\}$ is the coalition 
with individuals $i \in[(h-1) \Delta, h \Delta)$. Therefore, each citizen is a member of exactly one coalition. We define

- Rotating agenda setting (RoAS): Members of every coalition $h \in\{1, \ldots, N\}$ have the right to set the agenda only once within $N$ periods. The coalition that has the right to make a proposal in a particular period is chosen randomly from the set of coalitions which are eligible.

That is, coalitions that have set the agenda in a particular period in the time-interval $[0, t]$ are excluded from the agenda-setting process for $N-1$ future periods. We note that rotating agenda setting has been used in ancient Athens (Bleicken, 1991, pp. 183-184) and in the Roman Republic (Bleicken, 1989, p. 128). Bleicken (1991, p. 192) finds that, due to this rotation rule, more or less all Athenians participated directly in the city's decision-making in the course of time.

We assume that each member of a coalition $h$ receives the same subsidy $s_{t}$ (if $h$ receives subsidies at all) and that $\Delta$ is so small that $s_{t}=\frac{\psi \hat{\tau}}{\Delta}>\tilde{s}(0)$. In order to apply CIA $[a]$ we extend the reduced form $e_{i t}^{*}\left(x_{i t}\right)$ to the extended version: the optimal choice $e_{i t}^{*}(\cdot)$ is ultimately determined by the net income $w+f\left(x_{i t}\right)+s_{i t}-\tau_{i t}$, so that $e_{i t}^{*}=e_{i t}^{*}\left(w+f\left(x_{i t}\right)+\right.$ $\left.s_{i t}-\tau_{i t}\right)$. For some arbitrarily small $\epsilon(\epsilon>0)$ we define $\tilde{a}$ by $g\left(\tilde{x}+\epsilon, e^{*}(\tilde{a})\right)=\tilde{x}+\epsilon$. Thus, $\tilde{a}$ is - up to arbitrarily small reductions - the minimum level of net income required to have $x_{i t+1}>\tilde{x}$. We obtain

\section{Proposition 3}

A democracy with $\psi>0, C\{B C, C I A[a], R o A S, M V\}, a=\tilde{a}$, and $\Delta<\frac{\psi \hat{\tau}}{\tilde{s}(0)}$ can overcome poverty in finite time.

Proof : If a coalition $h$ can make a proposal they can generate aggregate subsidies of at least $\psi \hat{\tau}$ by the same argument as in Proposition 1 . Due to $\Delta<\frac{\psi \hat{\tau}}{\tilde{s}(0)}$ individual subsidies are higher than $\tilde{s}(0)$. Hence, all members of the coalition are set on a growth path. This occurs for all citizens during the $N$ periods according to the RoAS rule. Due to CIA $(a)$ a household that has once achieved a level of capital $\tilde{x}+\epsilon$ for some arbitrarily small $\epsilon$ will never fall below $\tilde{x}+\epsilon$. Hence, after $N$ periods, each citizen has at least a capital stock of $\tilde{x}+\epsilon$. Thus, the incomes of the entire society are growing. 
In the proof of Proposition 3, the CIA $(a)$ rule is applied such that the human capital stock is always higher than threshold $\tilde{x}$. This is a minimum requirement to be stated in constitution for overcoming poverty. ${ }^{10}$

Alternatively to the CIA rule, we can utilize the TFM rule for tax protection. In this case the tax allowance $\tilde{a}$ translates into a net income threshold $\bar{v}$ which requires unanimity as soon as any household's net income falls below $\bar{v}=\tilde{a} .{ }^{11}$

\section{Proposition 4}

A democracy with $\psi>0, C\{B C, T F M[\bar{v}], R o A S\}, \Delta<\frac{\psi \hat{\tau}}{\tilde{s}(0)}$, and $\bar{v}=\tilde{a}$ can overcome poverty in finite time.

Proof: See appendix.

\section{When Multiple Subsidization Is Required}

If $x_{i, t+1}^{\max }<\tilde{x}$, households subsidized once do not overcome poverty $\left(\gamma_{x_{i t}}<0\right)$ and have to be subsidized multiple for crossing threshold $\tilde{x}$. We use $r$ to denote the minimum number of periods a continuously subsidized household needs to accumulate capital $x_{i t}$ higher than $\tilde{x}$, when beneficiary households receive subsidy $\tilde{s}(0)$ in each period. ${ }^{12}$ We introduce

- Agenda repetition $(\mathrm{AR}[\mathrm{r}])$ : The agenda adopted in period $t$ has to be repeated $r$ times in the subsequent periods. Therefore, an agenda-setting coalition $h$ is only selected every $r$ elections.

We obtain

\section{Corollary 2}

A democracy with $\psi>0, C\{B C, C I A[a], \operatorname{RoAS}, M V, A R[r]\}, \Delta<\frac{\psi \hat{\tau}}{\tilde{s}(0)}$, and $a=\tilde{a}$ can overcome poverty in finite time even if $x_{i, t+1}^{\max }<\tilde{x}$.

\footnotetext{
${ }^{10}$ If the capital levels at present should be guaranteed as a kind of property right instead, one could also choose $a^{\prime}$ such that $g\left(x_{i t}, e_{i t}^{*}\left(a^{\prime}\right)\right)=x_{i t}$ holds. As said before, it is a priori unclear whether this accelerates the development process, however.

${ }^{11}$ The fixed net income threshold $\bar{v}$ is equivalent to an individual tax threshold $\bar{\tau}_{i t}=w+f\left(x_{i t}\right)-\tilde{a}$, which is equivalent to $\bar{\tau}_{i t}=\tilde{\tau}\left(x_{i t}\right)$.

${ }^{12}$ The size of subsidy $s_{t}$ could be lowered from period to period, because the level of capital in subsidized households is increasing: $\frac{\partial \tilde{s}\left(x_{i t}\right)}{\partial x_{i t}}<0$. However, such an adjustment is not part of the agenda adopted.
} 


\section{Corollary 3}

A democracy with $\psi>0, C\{B C, T F M[\bar{v}], \operatorname{RoAS}, A R[r]\}, \Delta<\frac{\psi \hat{\tau}}{\tilde{s}(0)}$, and $\bar{v}=\tilde{a}$ can overcome poverty in finite time even if $x_{i, t+1}^{\max }<\tilde{x}$.

Proof of Corollaries 2 and 3: The constitutional rule $A R[r]$ transplants the idea of multiple subsidization from Corollary 1 into a constitution. Hence, each member of the agenda setting coalition $h$ is set on a growth path after $r$ periods. Then, the logic of Propositions 3 and 4 applies for all $r$ periods.

\section{Discussion}

Our model identifies a variety of causes why democracies may fail to escape poverty. In this section, we briefly discuss sources of failure and how constitutional rules might cure such failure. In so doing, we relate our rules to rules in the constitutions of the U.S.A. and Germany.

(i) Expropriation of (non-poor) people

Adverse taxation of households that have already escaped poverty may take place, inducing these households to cut back investment and their level of capital to revert to the state of backwardness. We have shown that tax allowances and threshold-flexible majority rules can solve this problem. Recall that adverse taxation eventually leads to a complete loss of the capital stock owned. Hence, a related rule is Amendment IV to the U.S. constitution, where it is said that "The right of people to be secure ... against unreasonable .. seizures shall not be violated". In German constitutional law, a taxation practise is unconstitutional if disposable income after taxes is not sufficient to guarantee the constitutional private-property right set out in Article 14 (1). Such taxation is labeled excessively high ("strangulation tax"). The property-right protection rules in Amendment V to the U.S. constitution are thus also related.

(ii) Incomplete subsidization

There may be households that never benefit from any subsidization. One constitutional rule preventing incomplete subsidization is rotating agenda-setting, which means that each 
household has the right to set the agenda only once. In practice, the number of re-elections permitted for households and interest groups may be limited. Or certain preconditions are demanded to be qualified for office. We have shown how all poor households will be part of an agenda-setting coalition at some point in time and benefit from subsidies. Examples are the $22^{\text {nd }}$ Amendment to the U.S. Constitution that limits the number of reelections for the president to one. Similar rules have been established in Germany (Article 54, Basic Law, 2006 [1949]). In India, the $73^{\text {rd }}$ Amendment of the Constitution reserves a particular number of seats in parliaments for two disadvantaged minorities and for women (Duflo, 2005, p. 669). Hence, limiting agenda-setting rights is not unusual in democracy.

Another form of incomplete subsidization is that one-time support may be insufficient for beneficiaries to permanently escape poverty. This problem has been cured by the agenda repetition rule. It guarantees a sustainable economic development process and prevents that improvements materialize only temporary.

(iii) Quasi-monopolistic agenda-setting

Uneducated, poor citizens are disadvantaged. Therefore, they are only weakly represented in policy. This means that, although all people have the constitutional right to set an agenda, only a few rich households are actually in a position to do so. As a result, the same households may always get subsidized and attract rents. Consequently agenda-setter dynasties and benefiting networks establish. This problem can be explicitly dealt with by rotating agenda-setting.

There are a variety of other conceivable sources for political failure that does not stem directly from our model. Moreover, even if a constitution is well designed, politicians may become adept at circumventing its constraints to further their political ends (Grossman and Helpman, 1998). Hence, the risk of falling back into poverty will remain.

\section{Conclusions}

We have highlighted the fragility of democracy in the promotion of economic growth. We have identified that a set of rules can reduce this fragility and allow a society to overcome poverty. Besides majority voting, these rules include rotating agenda-setting, agenda repetition and tax protection rules. Though in our model, democracy is not subject to 
fraud or corruption, our analysis thus suggests that democratization in the narrow sense of majority voting per se is not sufficient to generate economic well-being.

We finally discuss whether elites ruling a non-democratic or a dysfunctional state would be interested in introducing these rules. There are two reasons why this may happen: First, as many developing countries are dependent on foreign aid, international donors could establish incentives for elites to adopt growth-promoting constitutions. Second, as the elites own most of the other production factors (land, capital, intangible assets), the education of the poor is sometimes in their own interest (Bourguignon and Verdier, 2000; Poutvaara, 2003). ${ }^{13}$ Following Acemoglu and Robinson (2000) and Bourguignon and Verdier (2000) extension of voting rights and democratization can be interpreted as strategic decision of elites to prevent social unrest or revolution and to benefit from higher returns of their assets. Our analysis highlights how those reforms must be designed in order to be successful in the long-term. Overall, we thus complement the insights provided by Persson and Tabellini (2006), who emphasize that the effect of democratization on growth depends on the details of carefully considered democratic reforms.

\footnotetext{
${ }^{13}$ This will not be the case if elites use technologies that are based on pure labor (Siemers, 2005, p. 205).
} 


\section{References}

Acemoglu, Daron and James A. Robinson, "Why Did the West Extend the Franchise? Democracy, Inequality, and Growth in Historical Perspective," Quarterly Journal of Economics, November 2000, 115 (4), 1167-1199.

Aghion, Philippe, Alberto Alesina, and Francesco Trebbi, "Endogenous Political Institutions," Quarterly Journal of Economics, May 2004, 119 (2), 527-564.

- and Patrick Bolton, "Incomplete Social Contracts," Journal of the European Economic Association, March 2003, 1 (1), 38-67.

Alesina, Alberto and Dani Rodrik, "Distributive Politics and Economic Growth," Quarterly Journal of Economics, 1994, 109, 465-490.

Baland, Jean-Marie and James A. Robinson, "Is Child Labor Inefficient?," Journal of Political Economy, 2000, 108 (4), 663-679.

Banerjee, Abhijit V. and Andrew F. Newman, "Occupational Choice and the Process of Development," Journal of Political Economy, April 1993, 101 (2), 274-298.

Baron, David P. and John Ferejohn, "Bargaining in Legislatures," The American Political Science Review, December 1989, 83 (4), 1181-1206.

Barro, Robert J., "Democracy and Growth," Journal of Economic Growth, 1996, 1 (1), $1-27$.

Basic Law, Basic Law for the Federal Republic of Germany, Parliamentary Council and German Bundestag, Bonn, Berlin 2006 [1949]. http://www.bundestag.de, accessed 12 October 2006.

Basu, Kaushik, "Child Labor: Cause, Consequence, and Cure, with Remarks on International Labor Standards," Journal of Economic Literature, 1999, 37 (3), 1083-1119.

Bell, Clive and Hans Gersbach, "Child Labor and the Education of a Society," Macroeconomic Dynamics, 2009, 13 (2), 220-249.

Bernholz, Peter and Friedrich Breyer, Grundlagen der Politischen Ökonomie, Vol. 2, J.C.B. Mohr (Paul Siebeck) Tübingen, 1994. 
Bleicken, Jochen, Die Verfassung der Römischen Republik: Grundlagen und Entwicklung, 5th ed., Verlag Ferdinand Schöningh, Paderborn, 1989.

_ , Die athenische Demokratie, 3rd ed., Verlag Ferdinand Schöningh, Paderborn, 1991.

Bourguignon, François and Thierry Verdier, "Oligarchy, Democracy, Inequality and Growth," Journal of Development Economics, 2000, 62 (2), 285-313.

Brennan, Geoffrey and Giuseppe Eusepi, "Fiscal Constitutionalism," in Jürgen G. Backhaus and Richard E. Wagner, eds., Handbook of Public Finance, Springer, 2005, chapter 3, pp. 53-76.

_ , "Homo Economicus and Homo Politicus: An introduction," Public Choice, 2008, 137 (3-4), 429-438.

Brueckner, Jan K. and Amihai Glazer, "Urban Extremism," The Journal of Law, Economics, \& Organization, 2007, 24 (2), 307-318.

Buchanan, James M. and Gordon Tullock, The Calculus of Consent: Logical Foundations of Constitutional Democracy, University of Michigan Press, 1962.

Duflo, Esther, "Why Political Reservations?," Journal of the European Economic Association, April-May 2005, 3 (2-3), 668-678.

Durham, J. Benson, "Economic Growth and Political Regimes," Journal of Economic Growth, 1999, 4 (1), 81-111.

Frey, Bruno S. and Alois Stutzer, "Strengthening the Citizens' Role in International Organizations," The Review of International Organizations, March 2006, 1 (1), 27-43.

_, Democratic Economic Policy - A Theoretical Introduction, Oxford: Martin Robertson \& Company, 1983.

Galor, Oded and Joseph Zeira, "Income Distribution and Macroeconomics," The Review of Economic Studies, January 1993, 60 (1), 35-52.

Gersbach, Hans and Lars-H. Siemers, "Land Reforms and Economic Development," Macroeconomic Dynamics, 2009, (forthcoming). 
_ , "Dividing Resources by Flexible Majority Rules," Social Choice and Welfare, October 2004, 23 (2), 295-308.

_, Designing Democracy: Ideas for Better Rules, Springer, Heidelberg, 2005.

Glaeser, Edward L. and Andrei Shleifer, "The Curley Effect: The Economics of Shaping the Electorate," The Journal of Law, Economics, $\&$ Organization, 2005, 21 (1), 1-19.

Gradstein, Mark and Moshe Justman, "Democratic Choice of an Education System: Implications for Growth and Income Distribution," Journal of Economic Growth, 1997, $2(2), 169-183$.

Grant, R.W., "Passions and interests revisited: The psychological foundations of economics and politics," Public Choice, 2008, 137 (3-4), 451-461.

Grossman, Gene M. and Elhanan Helpman, "Intergenerational Redistribution with Short-Lived Governments," The Economic Journal, September 1998, 108 (450), 12991329.

Helpman, Elhanan, "Politics and Trade Policy," in D. M. Kreps and K. F. Wallis, eds., Advances in Economics and Econometrics: Theory and Applications, Cambridge University Press, New York, 1997, pp. 19-45.

Keefer, Philip and Razvan Vlaicu, "Democracy, Credibility, and Clientelism," The Journal of Law, Economics, $\mathscr{G}$ Organization, 2007, 24 (2), 371-406.

Knack, Stephen and Philip Keefer, "Institutions and Economic Performance: CrossCountry Tests Using Alternative Institutional Measures," Economics and Politics, November 1995, 7 (3), 207-227.

Mueller, Dennis C., Robert D. Tollison, and Thomas D. Willett, "Representative Democracy via Random Selection," Public Choice, 1972, 12 (1), 57-69.

_ , Public Choice, Cambridge University Press, 1979.

_ , Public Choice III, 6th printing ed., Cambridge University Press, 2006. 
Paldam, Martin and Erich Gundlach, "Two Views on Institutions and Development: The Grand Transition vs. the Primacy of Institutions," Kyklos, 2008, 61 (1), 65-100.

_ , "The big pattern of democracy - A study of the Gastil Index," in A. Marciano and J.M. Josselin, eds., Democracy, Freedom and Coercion: A Law and Economics Approach, Cheltenham: Edward Elgar, 2007.

Perotti, Roberto, "Income Distribution, Politics, and Growth," The American Economic Review, May 1992, 82 (2), 311-316.

_ , "Political Equilibrium, Income Distribution, and Growth," The Review of Economic Studies, October 1993, 60 (4), 755-776.

_ , "Growth, Income Distribution, and Democracy: What the Data Say," Journal of Economic Growth, 1996, 1 (1), 149-187.

Persson, Torsten and Guido Tabellini, "Is Inequality Harmful for Growth?," The American Economic Review, June 1994, 84 (3), 600-621.

_ and _, "Democracy and Development: The Devil in the Details," The American Economic Review, May 2006, 96 (2), 319-324.

Poutvaara, Panu, "Gerontocracy Revisited: Unilateral Transfer to The Young May Benefit the Middle-Aged," Journal of Public Economics, 2003, 88 (1-2), 161-174.

Rangel, Antonio, "How to Protect Future Generations Using Tax-Base Restrictions," The American Economic Review, March 2005, 95 (1), 314-346.

Riker, William H., The Theory of Political Coalitions, Yale University Press, 1962.

Saint-Paul, Gilles and Thierry Verdier, "Education, Democracy and Growth," Journal of Development Economics, December 1993, 42 (2), 399-407.

_ and _, "Inequality, Redistribution and Growth: A Challenge to the Conventional Political Economy Approach," European Economic Review, April 1996, 40 (3-5), 719 728.

Shughart, W. F. II and R. D. Tollison, "Public Choice in the new century," Public Choice, 2005, 124 (1), 1-18. 
Siemers, Lars-H., How to Overcome Poverty Traps by Education, Ruprecht-KarlsUniversity at Heidelberg, 2005. Doctoral thesis, http://www.ub.uni-heidelberg.de/ archiv/5363.

Tavares, José and Romain Wacziarg, "How Democracy Affects Growth," European Economic Review, 2001, 45 (8), 1341-1378. 


\section{Appendix}

\section{A A Specific Example}

As an example, consider the following Stone-Geary utility function:

$$
U_{i t}= \begin{cases}c_{i t} & \text { if } c_{i t} \leq \bar{c} \\ \bar{c}+\left(c_{i t}-\bar{c}\right) \cdot x_{i, t+1} & \text { otherwise }\end{cases}
$$

Let $g\left(x_{i t}, e_{i t}\right)=\rho x_{i t}+e_{i t}$, where $\rho \in(0,1)$ represents the transmission factor between generations. ${ }^{14}$ As individuals demand a minimal consumption of $\bar{c}$ before they start to invest, we have $c^{*}\left(x_{i t}\right)=w+f\left(x_{i t}\right)$ and $e^{*}\left(x_{i t}\right)=0$ if $w+f\left(x_{i t}\right) \leq \bar{c}$ (corner solution). Applying equations (1) and (2) and solving for $e_{i t}$, we obtain the interior solution

$$
e^{*}\left(x_{i t}\right)=\frac{1}{2}\left[w+f\left(x_{i t}\right)-\rho x_{i t}-\bar{c}\right]
$$

with $\frac{\partial e^{*}\left(x_{i t}\right)}{\partial\left(w+f\left(x_{i t}\right)\right)}>0, \frac{\partial e^{*}\left(x_{i t}\right)}{\partial\left(\rho x_{i t}\right)}<0$, and $\frac{\partial e^{*}\left(x_{i t}\right)}{\partial \bar{c}}<0$. Accordingly, we obtain $c^{*}\left(x_{i t}\right)=$ $\frac{1}{2}\left[w+f\left(x_{i t}\right)+\rho x_{i t}+\bar{c}\right]$. Our assumption $\frac{\partial e^{*}\left(x_{i t}\right)}{\partial x_{i t}}>0$ requires $f^{\prime}\left(x_{i t}\right)>\rho$. Suppose, for instance, $f\left(x_{i t}\right)=\alpha x_{i t}$. Then we would require $\alpha>\rho$. In this case, we obtain from (13) that $\bar{x}=\frac{\bar{c}-w}{\alpha-\rho}$. That is, the critical threshold of capital is determined by the difference between $\bar{c}$ and labor income $w$, divided by the difference of the technology parameters $\alpha$ and $\rho$. The higher the productivity of capital $(\alpha)$ is, the lower is the level of capital at which the household starts investing. By contrast, the higher the transmission factor $\rho$ is, the less important investment in capital becomes, since more capital is transferred to the child.

We next discuss $\frac{\mathrm{d} x_{i, t+1}}{\mathrm{~d} x_{i t}}=\frac{\partial g\left(x_{i t}\right)}{\partial e_{i t}} \cdot \frac{\partial e^{*}\left(x_{i t}\right)}{\partial x_{i t}}+\frac{\partial g\left(x_{i t}\right)}{\partial x_{i t}}$. We have $\frac{\partial e^{*}\left(x_{i t}\right)}{\partial x_{i t}}=\frac{1}{2}(\alpha-\rho)>0$. For $x_{i t}>\bar{x}$ the slope is given by $\frac{1}{2}(\alpha+\rho)>1$, and for $x_{i t} \leq \bar{x}$ it is given by $\rho$. We obtain $\tilde{x}=\frac{\bar{c}-w}{\alpha+\rho-2}$. That is, the critical capital threshold to be crossed in order to escape the poverty trap increases with the difference between minimal consumption $\bar{c}$ and labor income $w$. The higher $\bar{c}-w$ is, the more capital income is required to close the gap. Moreover, the threshold decreases with $\alpha$ and $\rho$, as capital is more productive. Finally, the growth rate of capital in the area $x_{i t}>\bar{x}$ is given by

$$
\gamma_{x_{i t}}=\frac{\alpha+\rho}{2}-1-\frac{\bar{c}-w}{2 x_{i t}} .
$$

\footnotetext{
${ }^{14}$ That is, $1-\rho$ represents the depreciation rate.
} 
That is, the growth rate of capital increases with the individual level of capital $x_{i t}$ and asymptotically approaches $\frac{\alpha+\rho}{2}-1$, that is, $\lim _{x_{i t} \rightarrow \infty} \gamma_{x_{i t}}=\frac{\alpha+\rho}{2}-1>0$.

\section{B Proofs}

Proof of Proposition 4: By the same argument as in Proposition 3 all members of the agenda setting coalition $h$ are set on a growth path. Due to TFM $[\bar{v}]$ a household that has once achieved a level of capital $\tilde{x}+\epsilon$ for some arbitrarily small $\epsilon$ will never fall below $\tilde{x}+\epsilon$, because if a proposal would involve this scenario, the citizen concerned can and will veto. Hence, after $N$ periods, each citizen has at least a capital stock of $\tilde{x}+\epsilon$ and the incomes of the entire society are growing. 


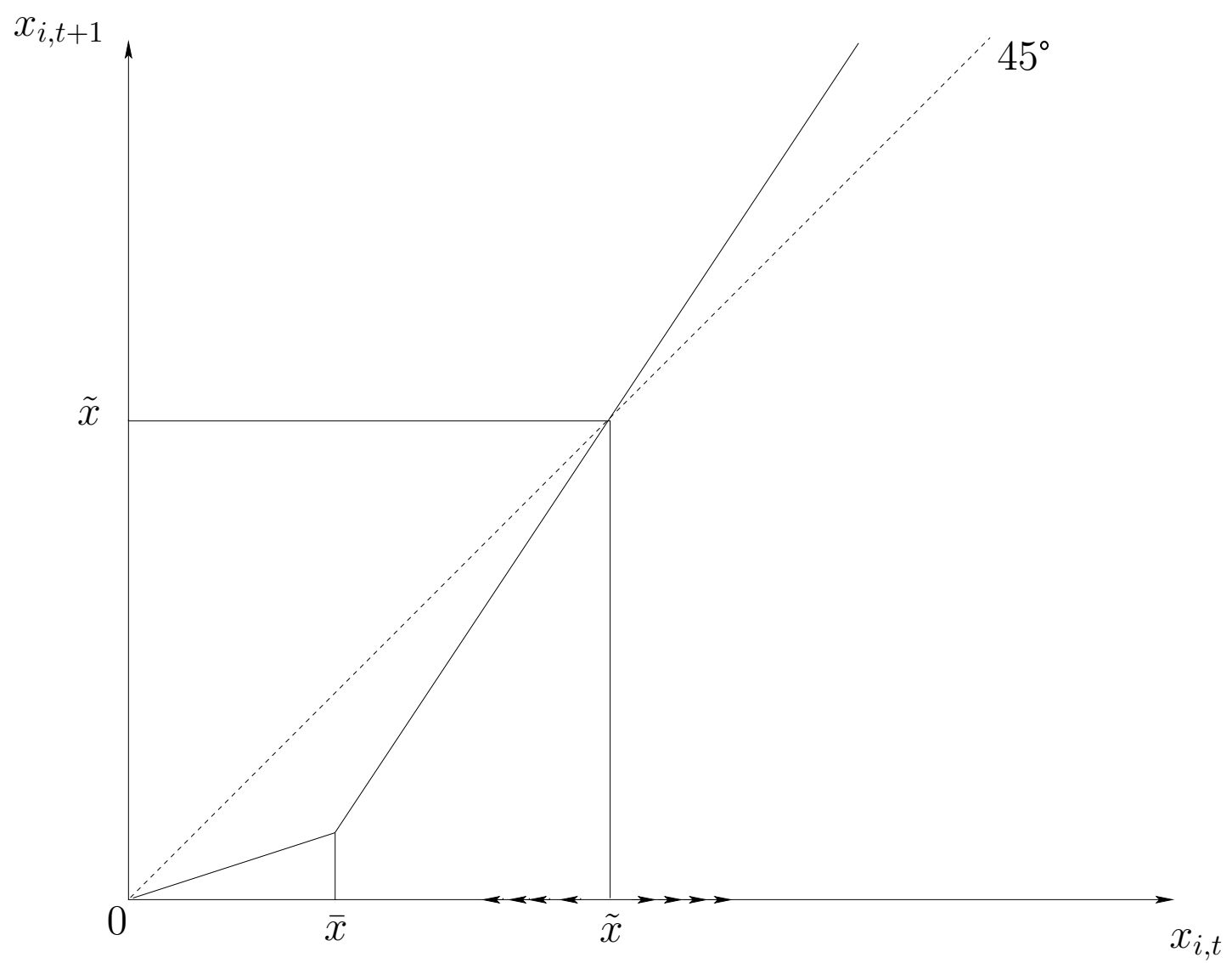

Figure 1: Model dynamics in the phase diagram 